\title{
Cellular angiofibroma: analysis of 25 cases emphasizing its relationship to spindle cell lipoma and mammary-type myofibroblastoma
}

\author{
Uta Flucke $^{1}$, J Han JM van Krieken ${ }^{1}$ and Thomas Mentzel ${ }^{2}$ \\ ${ }^{1}$ Department of Pathology, Radboud University Nijmegen Medical Centre, Nijmegen, The Netherlands and \\ ${ }^{2}$ Dermatopathologie Bodensee, Friedrichshafen, Germany
}

\begin{abstract}
Cellular angiofibroma represents a rare benign mesenchymal tumor, occurring mainly in the superficial soft tissue of the genital region. The involvement of $13 q 14$ in some cases confirmed the morphological suggested link with spindle cell lipoma and mammary-type myofibroblastoma. We analyzed the clinicopathological and immunohistochemical features of 25 cases, and performed in a number of cases additional molecular studies. There were 17 female and 8 male patients (age ranged from 27 to 83 years); females tended to be younger. A marked predilection for the vulva $(n=13)$ was observed, and neoplasms in males were predominantly located in the inguinal region $(n=4)$, and one case each in the scrotum, perianal, the knee, and the upper eyelid. The tumors arose most commonly in the superficial soft tissue and were well circumscribed in all but two cases. The tumor size ranged from 1 to $9 \mathrm{~cm}$. All lesions were composed of spindle-shaped cells associated with numerous small- to medium-sized blood vessels; however, a broad morphological variation with foci of lipogenic differentiation in nine cases and sarcomatous transformation in one case was found. By immunohistochemistry, 11 out of 22 cases expressed CD34. A focal reaction for $\alpha$-smooth muscle actin was observed in 9 out of 22 cases, and two cases each stained weak and focally positive for epithelial membrane antigen and CD99. In all seven cases tested, a monoallelic deletion of RB1 was detected by FISH analysis. Follow-up, available in 14 patients, showed neither local recurrence nor metastasis. In conclusion, we affirm the link between cellular angiofibroma, spindle cell lipoma, and mammary-type myofibroblastoma, showing a spectrum of one entity with morphological variations dependent on anatomic location.

Modern Pathology (2011) 24, 82-89; doi:10.1038/modpathol.2010.170; published online 17 September 2010
\end{abstract}

Keywords: cellular angiofibroma; genital mesenchymal tumors; mammary-type myofibroblastoma; soft tissue; spindle cell lipoma

Cellular angiofibroma, first described in 1997 by Nucci et al, ${ }^{1}$ is an uncommon benign mesenchymal tumor occurring mainly in the genital region of both genders. $^{2,3}$ Extragenital localizations are also known; however, most of the lesions are assigned to the pelvic area. ${ }^{1-7}$ They are commonly well circumscribed, localized in the superficial soft tissue, and characterized by bland spindle-shaped cells arranged without any pattern in a stroma with wispy collagen and numerous small- to medium-sized thick-walled vessels. ${ }^{1-3}$

Correspondence: Dr U Flucke, MD, Department of Pathology, Radboud University Nijmegen Medical Centre, PO Box 9101, Nijmegen 6500HB, The Netherlands.

E-mail: U.Flucke@pathol.umcn.nl

Received 12 March 2010; revised 5 July 2010; accepted 11 July 2010; published online 17 September 2010
More recently, atypical features and sarcomatous transformation of cellular angiofibroma have been reported. Whereas in some cases, areas of pleomorphic spindle cells were examined, others contained a well-differentiated liposarcoma or a pleomorphic liposarcoma component, but in neither of these patients a poor outcome was present. ${ }^{3,6,8}$

The histomorphological and, to a lesser extent, immunohistochemical overlap of cellular angiofibroma with spindle cell lipoma and mammary-type myofibroblastoma suggested a possible link among them. ${ }^{1-3,9-11}$ Subsequently, a monoallelic loss of $R B 1$ and FOXO1, located on 13q14 was found in some of these tumor types supporting the notion that they may belong to a spectrum. ${ }^{12-16}$

We report on 25 additional cases of CAF to widen the clinicopathological features with an additional morphologically sarcomatous transformed 
case, and underpin the genetic relationship with mammary-type myofibroblastoma and spindle cell lipoma.

\section{Materials and methods}

The cases were retrieved from the authors' referral files, and clinical details and follow-up were obtained from the referring pathologists (see acknowledgement). In all cases, the tissue was fixed in $4 \%$ buffered formalin, routinely processed, and embedded in paraffin; $2-4 \mu \mathrm{m}$ thick sections were stained with hematoxylin and eosin and immunohistochemically by the labeled Streptavidin Biotin technique using commercially available antibodies listed in Table 1. Antigen retrieval was performed for all of them. Appropriate positive and negative controls were used throughout.

FISH analysis for the detection of $R B 1$, located on 13q14.2, was performed in seven cases with a direct spectrum orange-labeled probe (Abbott, Bergisch Gladbach, Germany) on $3 \mu \mathrm{m}$ sections of formalinfixed, paraffin-embedded tissue after baking at $65^{\circ} \mathrm{C}$ for $16 \mathrm{~h}$, deparaffinization with xylene, and dehydration with ethanol. All tissue sections were pretreated with a $30 \%$ solution of Oncor pre-treatment solution and digested with Proteinase $\mathrm{K}$ following the instructions of the suppliers (Q-Biogene, Heidelberg, Germany). Digestion times were optimized on a case-by-case basis. After a second dehydration step, the probes were applied to the sections and the covered slides were sealed with rubber cement, heat -denatured, and hybridized at $37^{\circ} \mathrm{C}$ for $16 \mathrm{~h}$. One positive (spindle cell lipoma) and one negative control (normal tissue) were included in each FISH series.

After stringent washing with $50 \%$ formamide in $2 \times$ SSC and treating with FITC anti-DIG in case of the indirectly labeled probes, the sections were counterstained with DAPI II in mounting medium (125 ng/ml, Abbott) and visualized under a Zeiss Axioplan 2 microscope using an HBO103 lamp and the appropriate filters for three fluorescence dyes.

Table 1 Details of used immunohistochemical antibodies

\begin{tabular}{llcl}
\hline Antibody & Clone & Dilution & Source \\
\hline ASMA & 1A4 & $1: 500$ & DAKO \\
Desmin & D33 & $1: 200$ & DAKO \\
CD117 & Polyclonal & $1: 100$ & DAKO \\
EMA & Mc5 & $1: 400$ & BioGenex, \\
& & & San Ramon, USA \\
CD34 & HPCA-1 & $1: 100$ & BD Biosciences, \\
& & & San Jose, USA \\
Pancytokeratin & MNF116 & $1: 500$ & DAKO \\
S-100 protein & Polyclonal & $1: 2000$ & DAKO \\
h-Caldesmon & h-CD & $1: 200$ & DAKO \\
CD31 & JC70A & $1: 100$ & DAKO \\
CD99 & 12E7 & $1: 500$ & DAKO \\
& & & \\
\hline
\end{tabular}

\section{Results}

\section{Clinical Findings}

Clinical details are summarized in Table 2. Briefly, the neoplasms arose in 17 female and 8 male patients. The age range was 27-83 years (mean: 52 years; median: 50 years). Women tended to be younger (age range: 27-63 years; mean: 47 years; median: 47 years) than men (age range: $32-83$ years; mean: 63 years; median: 67 years). Tumors arising in female patients were predominantly seen in the vulva $(n=13)$. Four of them were assigned to the labia majora and one to the clitoris. One case each was located in the vaginal introitus, vaginal fornix, perineum, and the knee. Lesions in male patients were seen in the inguinal region $(n=4)$, the scrotum $(n=1)$, in the perianal region $(n=1)$, the knee $(n=1)$, and the upper eyelid $(n=1)$. All patients underwent simple local excision. Complete excision was reached in 13 cases and re-excision with subsequent tumor-free margins was performed in one case (Case 2). Marginal excision was verified in four cases and positive margins were reported in seven cases. The resection status was not known for Case 21.

Follow-up, available for 14 patients, ranged from 6 to 110 months (mean: 37 months; median: 34 months). It was unremarkable for all patients. Case 5

Table 2 Clinical data of 25 cases of cellular angiofibroma

\begin{tabular}{|c|c|c|c|c|c|}
\hline Case & Sex/age & Site & $\begin{array}{l}\text { Size } \\
(\mathrm{cm})\end{array}$ & Treatment & $\begin{array}{l}\text { Follow-up } \\
\text { (mos) }\end{array}$ \\
\hline 1 & $\mathrm{~m} / 48$ & Scrotum & 9 & R0 & 110, NER \\
\hline 2 & $f / 41$ & Perineal & 3 & Ro & NA \\
\hline 3 & $\mathrm{~m} / 75$ & Groin & 6.5 & Ro & 48, NER \\
\hline 4 & $f / 39$ & Vaginal introitus & 1 & $\mathrm{R} 1$ & 75, NER \\
\hline 5 & $f / 50$ & Vulva & 3 & R1 & 55, NER \\
\hline 6 & $f / 51$ & Labium majus & 2.7 & $\mathrm{ME}$ & 66, NER \\
\hline 7 & $f / 44$ & Labium majus & 2.3 & Ro & NA \\
\hline 8 & $f / 50$ & Vulva & 4 & R2 & NA \\
\hline 9 & $f / 63$ & Knee lateral & 4 & R0 & 45, NER \\
\hline 10 & $\mathrm{f} / 48$ & Vulva & 8.5 & R0 & NA \\
\hline 11 & $f / 42$ & Vulva & 2.2 & R0 & NA \\
\hline 12 & $f / 63$ & Klitoris & 2.5 & R1 & 38, NER \\
\hline 13 & $\mathrm{f} / 27$ & Labium majus & 8 & $\mathrm{ME}$ & NA \\
\hline 14 & $f / 42$ & Vulva & 1.7 & Ro & 30, NER \\
\hline 15 & $\mathrm{f} / 46$ & Labium majus & 3 & ME & NA \\
\hline 16 & $\mathrm{~m} / 83$ & Inguinal canal & 2 & Ro & NA \\
\hline 17 & $f / 55$ & Vulva & 2.3 & R0 & 12, NER \\
\hline 18 & $\mathrm{~m} / 77$ & Inguinal canal & 4.5 & Ro & NA \\
\hline 19 & $\mathrm{~m} / 56$ & Inguinal canal & 3 & R0 & 6, NER \\
\hline 20 & $\mathrm{~m} / 77$ & Knee & 5.1 & Ro & 11, NER \\
\hline 21 & $f / 57$ & Vulva & 4.5 & $\mathrm{RX}$ & 6, NER \\
\hline 22 & $\mathrm{f} / 47$ & Vulva & 1.5 & R1 & NA \\
\hline 23 & $\mathrm{~m} / 32$ & Upper eyelid & 1.2 & R1 & 6, NER \\
\hline 24 & $\mathrm{~m} / 59$ & Perianal & 8 & R1 & 7, NER \\
\hline 25 & f/39 & Vaginal fornix & 9 & $\mathrm{ME}$ & Recently \\
\hline
\end{tabular}

m, male; f, female; R0, complete excision; ME, marginal excision; R1, local excision with histologically positive margins; R2, local excision with macroscopically positive margins; RX, local excision, margins not known; NA, information not available; NER, no evidence of recurrence. 
most likely represents a relapse of an 11 years earlier excised tumor.

Given clinical diagnoses were (Bartholin) cyst, polyp, myoma, atheroma, pilomatricoma, or lacrimal gland carcinoma. The last two diagnoses were assigned to the tumor in the upper eyelid.

\section{Pathological Findings}

Grossly, the neoplasms were described as white or yellowish nodules, mostly solid and partly gelatinous or cystic in appearance. Three tumors were recorded as polypoid lesions (Cases 11, 12, 25). The size ranged from 1 to $9 \mathrm{~cm}$ (mean: $4.1 \mathrm{~cm}$ ). Tumors in women inclined to be smaller (range: 1-9 cm; mean: $3.7 \mathrm{~cm}$ ) than in men (range: $1.2-9 \mathrm{~cm}$; mean: $4.9 \mathrm{~cm}$ ).

Histologically, most lesions were found in superficial soft tissue $(n=21)$ and all but two were well circumscribed. Nine tumors were at least partly encapsulated. An infiltrative growth was seen in Cases 5 and 21. The first was located in deep soft tissue, whereas the second showed features of sarcomatous transformation (see below). Three vulvar and one vaginal lesion were superficially located and showed an exophytic growth, one of them (Case 10) was ulcerated. In 11 cases, a multinodular growth with incomplete fibrous septa was noted. The spindle-shaped tumor cells were arranged haphazardly and showed organization partly in short fascicles in four cases. They had bland, oval to fusiform, and sometimes tapering nuclei. The cytoplasm was ill-defined, pale eosinophilic and had, if recognizable, bipolar processes (Figure 1). Nuclear grooves and intranuclear inclusions were commonly observed. In three cases (Cases 6, 7, 11), focal mild nuclear atypia with slightly enlarged nuclei was recognizable, and furthermore, in Case 11, some multinucleated cells were detected (Figure 2). Six cases featured mitotic figures, ranging from 1 to 3 mitoses per 10 highpower fields. A transformation from typical areas of CAF into cellular not well-delineated nodules composed of enlarged, highly pleomorphic, and multinucleated cells with prominent nuclear atypia and atypical mitoses was present in Case 21 (Figures $3-5)$. Thus, this part of the tumor has morphological features of malignancy.

All tumors contained wispy collagen; in addition, thicker collagen bundles were focally present in six cases. The vascular component, prominent in all lesions, consisted of small- to medium-sized vessels with mostly hyalinized walls (Figure 1). A hemangiopericytoma-like vascular pattern was observed in three cases (Cases 16, 19, 21) (Figure 6). Edematous changes of vessels due to chronic inflammation were seen in four cases and vascular thrombotic obliteration was observed in one case. Nine cases $(36 \%)$ included mature adipocytes, predominantly in peripheral areas, ranging from 1 to $30 \%$ of the

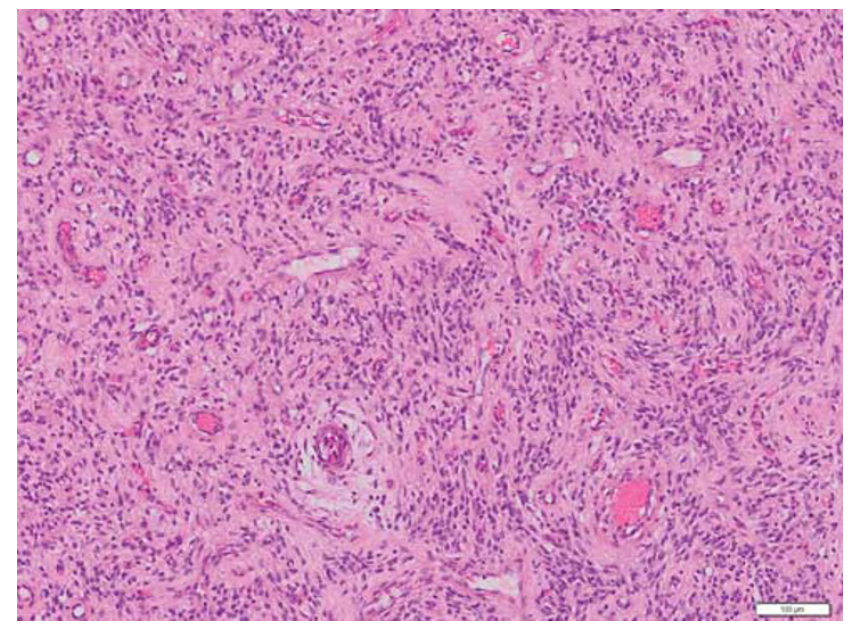

Figure 1 Typical features of CAF showing loosely arranged spindle cell lipoma-like cells and a prominent vasculature with thick vessel walls. There is a finely collagenous background (Case 3).

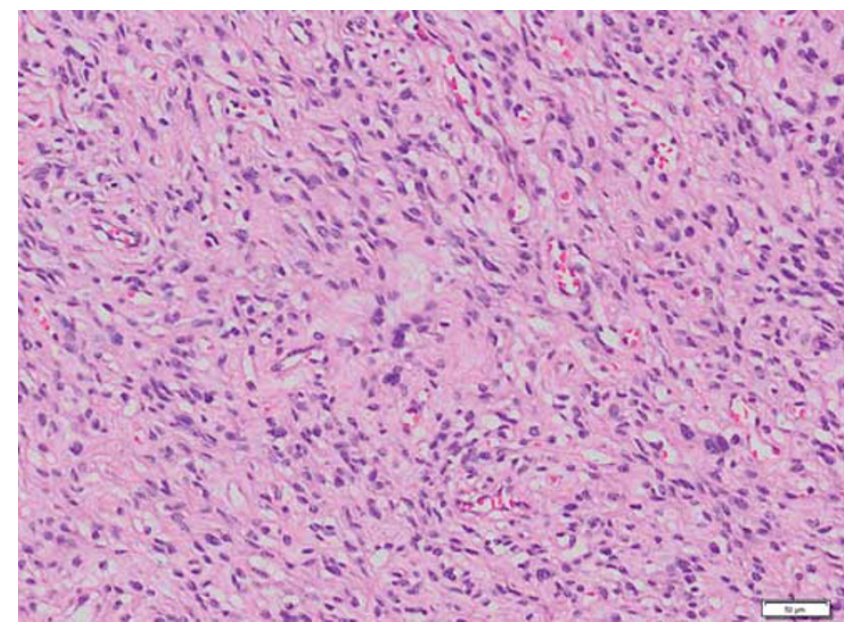

Figure 2 Mild nuclear atypia with slightly enlarged nuclei and multinucleated cells found in Case 11.

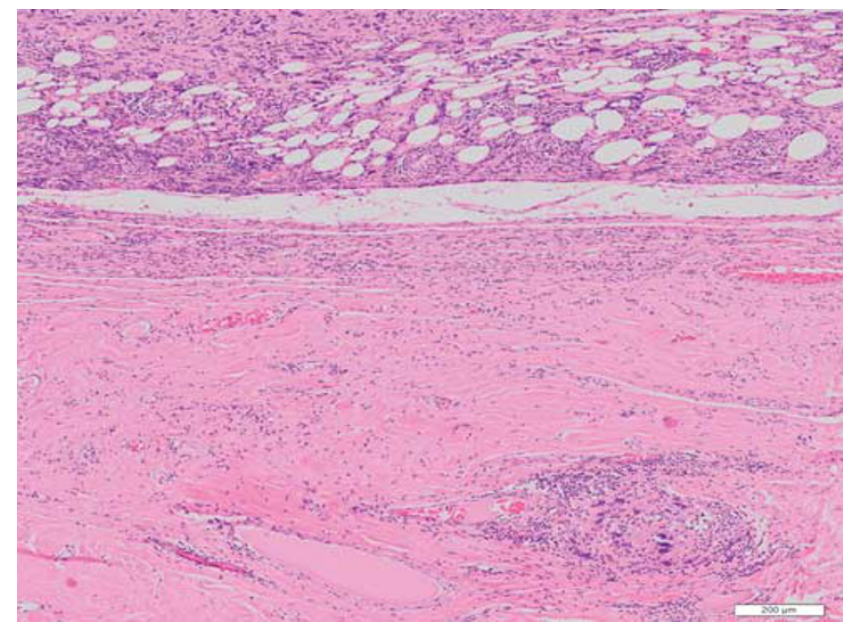

Figure 3 The sarcomatous transformed component in Case 21 was not well circumscribed and included mature adipocytes. 


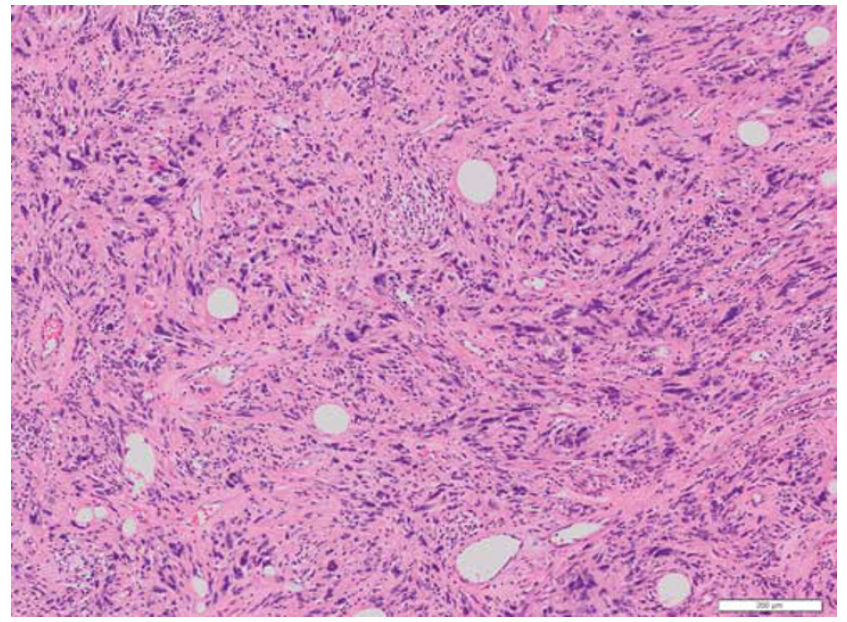

Figure 4 There are pleomorphic nuclei and a typical pattern of CAF with prominent hyalinized vessels (Case 21, malignant area).

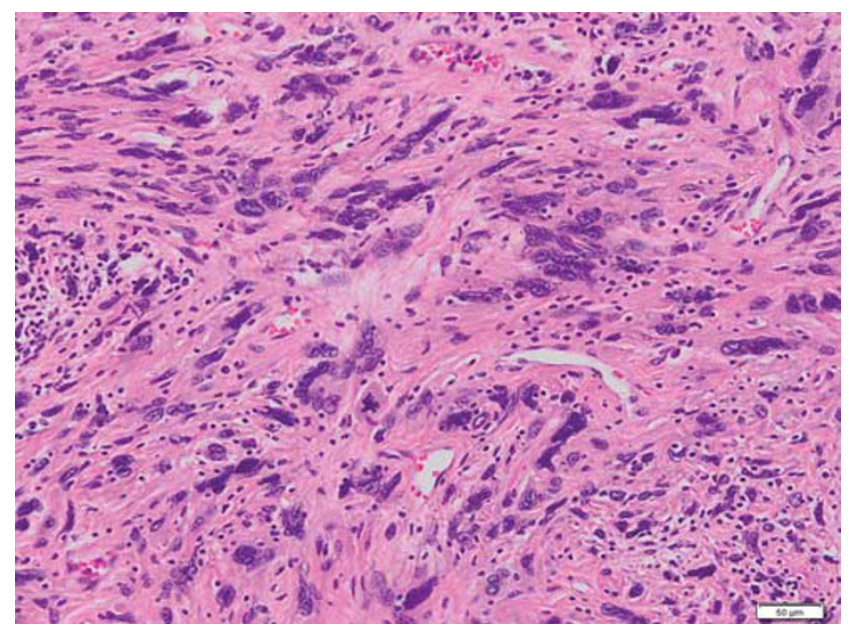

Figure 5 Pleomorphic tumor cells and atypical mitotic figures of the malignant areas of Case 21.

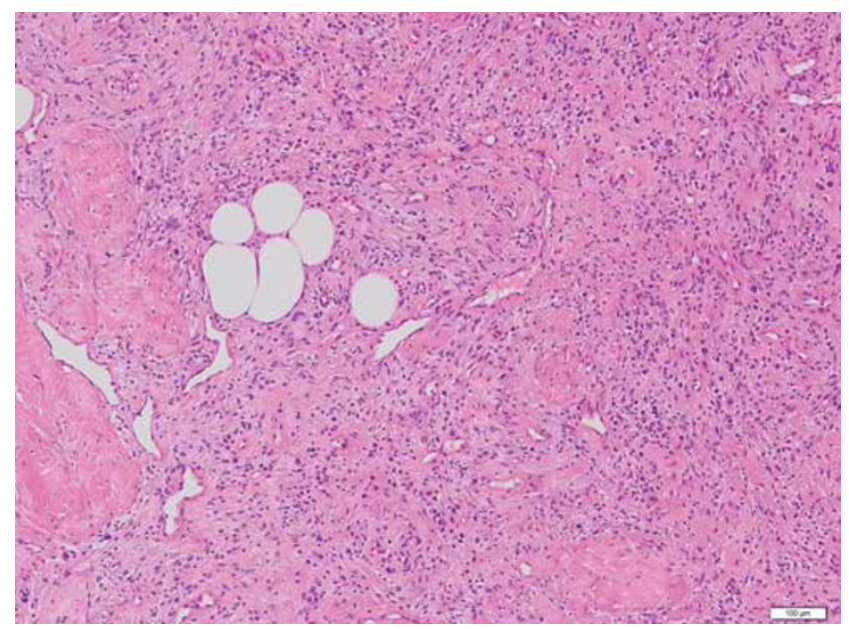

Figure 6 Case 16 shows hemangiopericytoma-like vessels and focal inclusion of adipocytes; broad collagen deposits are also seen.

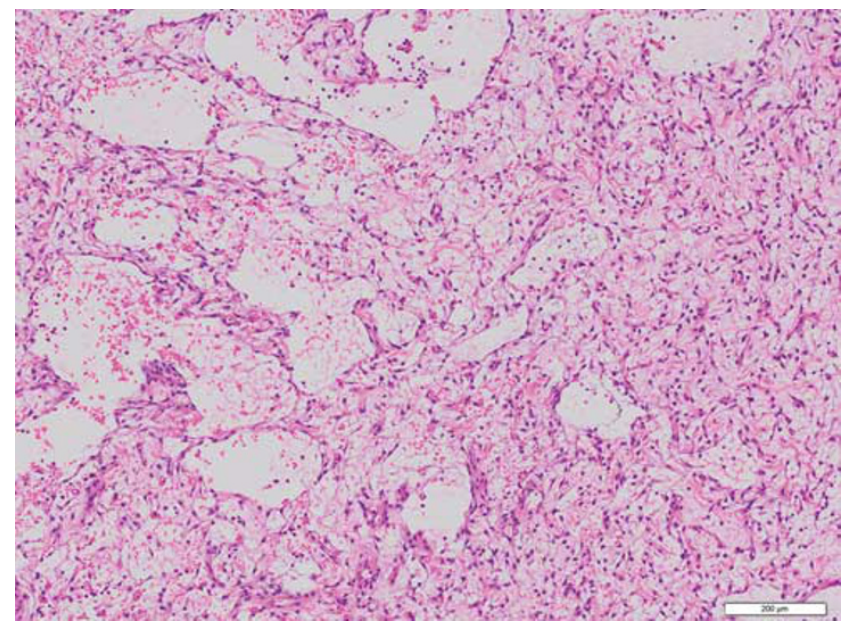

Figure 7 Prominent pseudovascular structures were found in three cases, as seen in Case 10.

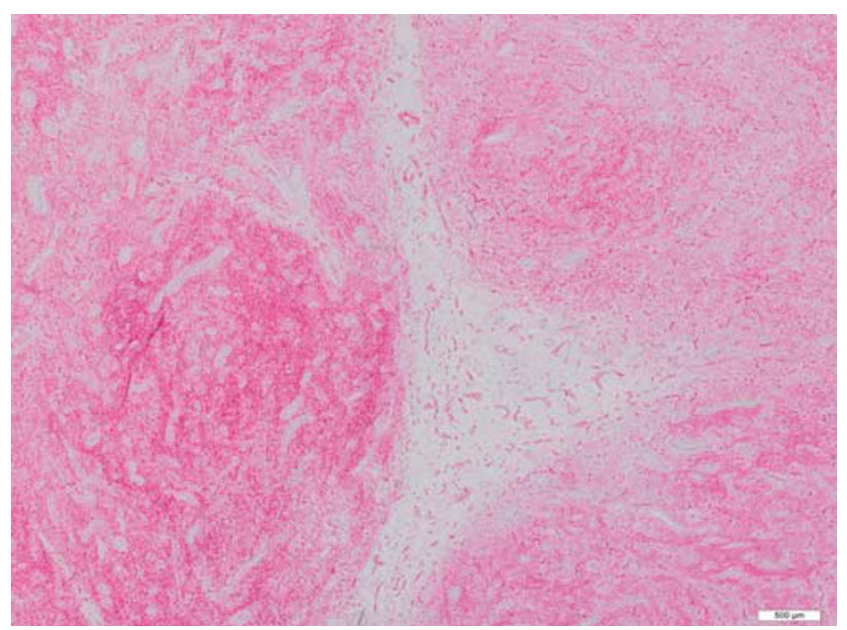

Figure 8 Strong CD34 positivity accented in Case 3 the multinodular architecture.

analyzed tumor area. Pseudovascular spaces filled with proteinaceous fluid were seen in three cases and microcystic changes in four cases (Figure 7). A total of 17 cases showed, at least focally, myxoid stromal changes, whereas a hyalinized background was noted in 10 cases. Scattered mast cells were found throughout the lesions, and lymphocytic aggregates, at least focally, were commonly present. Areas of hemorrhage or tumor necrosis were not observed.

Immunohistochemically, 11 out of 22 cases tested expressed CD34 (Figure 8); one of them was only focally positive. The $\alpha$-smooth muscle actin was focally detected in 9 out of 22 cases tested (40.9\%) and epithelial membrane antigen (EMA) in two out of six cases. CD99 was positive in two out of four cases. The remaining antibodies (desmin, h-caldesmon, S-100 protein, pancytokeratin, CD31) were negative in all cases tested. 
Seven cases analyzed by FISH exhibited a monoallelic deletion of the $R B 1$ in a considerable number of counted nuclei (Table 3; Figure 9).

\section{Discussion}

Cellular angiofibromas, most commonly described in the genital region of both genders, are rare benign mesenchymal neoplasms characterized by a bland spindle cell component and numerous small- to medium-sized vessels with mural hyalinization. Typically, there is a wispy collagenous, occasionally myxoid stroma. A mature adipocytic component is variably seen. ${ }^{1-3}$

A morphological overlap with spindle cell lipoma and mammary-type myofibroblastoma has been amply described. Whereas a more fascicular pattern has been attributed to the mammary-type myofibroblastoma, a more haphazard arrangement was observed in the other two neoplasms. On the other hand, ropey collagen is a characteristic finding in spindle cell lipoma and mammary-type myofibroblastoma. The striking hyalinized vessels are distinctive for cellular angiofibroma. ${ }^{1-3,9-11,17,18}$

Table 3 Results of RB1 FISH analyses

Case 9

Case 10

Case 15

Case 16

Case 17

Case 19

Case 25
Deletion in 33 out of 63 nuclei counted Deletion in 16 out of 49 nuclei counted Deletion in 27 out of 52 nuclei counted Deletion in 24 out of 51 nuclei counted Deletion in 19 out of 56 nuclei counted Deletion in 42 out of 56 nuclei counted Deletion in 26 out of 54 nuclei counted
There are few reported lesions in extragenital localizations, including retroperitoneum, pelvic and lumbal region, anus, urethra, trunk, and oral mucosa. ${ }^{3-7}$ Our files contained three extragenital tumors located on the knee $(n=2)$ and upper eyelid $(n=1)$. These cases also had classical histological features with obvious hyalinized vessels and, at least focally, finely collagenous background.

Mature adipocytes were found in approximately one-third and pseudovascular structures were present in three of our cases. These findings are in line with earlier descriptions. ${ }^{2,3,19}$

Immunohistochemically, expression of CD34 was seen in $50 \%$ of the cases tested, whereas none of our cases analyzed showed an expression of desmin in accordance with reports of others. ${ }^{2,3}$ In comparison, spindle cell lipoma and mammary-type myofibroblastoma are consistent positive for CD34 and the latter shows always coexpression of desmin. ${ }^{11}$

A genetic link between cellular angiofibroma, mammary-type myofibroblastoma, and spindle cell lipoma was shown in some cases, all showing a typical loss of genetic material from the 13q14 region, as indicated by monoallelic deletion of RB1 and FOXO1. ${ }^{14,16}$ Herein, we proved by FISH the heterozygote loss of $R B 1$ in all examined cases $(n=7)$, thus confirming this relationship.

Hitherto, there are few reported cases of cellular angiofibroma with atypia or sarcomatous features. One case was located in the subcutis of the iliacal region and the others were localized in the vulva. Two cases contained areas of a pleomorphic liposarcoma and three of an atypical lipomatous tumor. $^{3,8}$ Our transformed case was akin to a malignant solitary fibrous tumor with pleomorphic

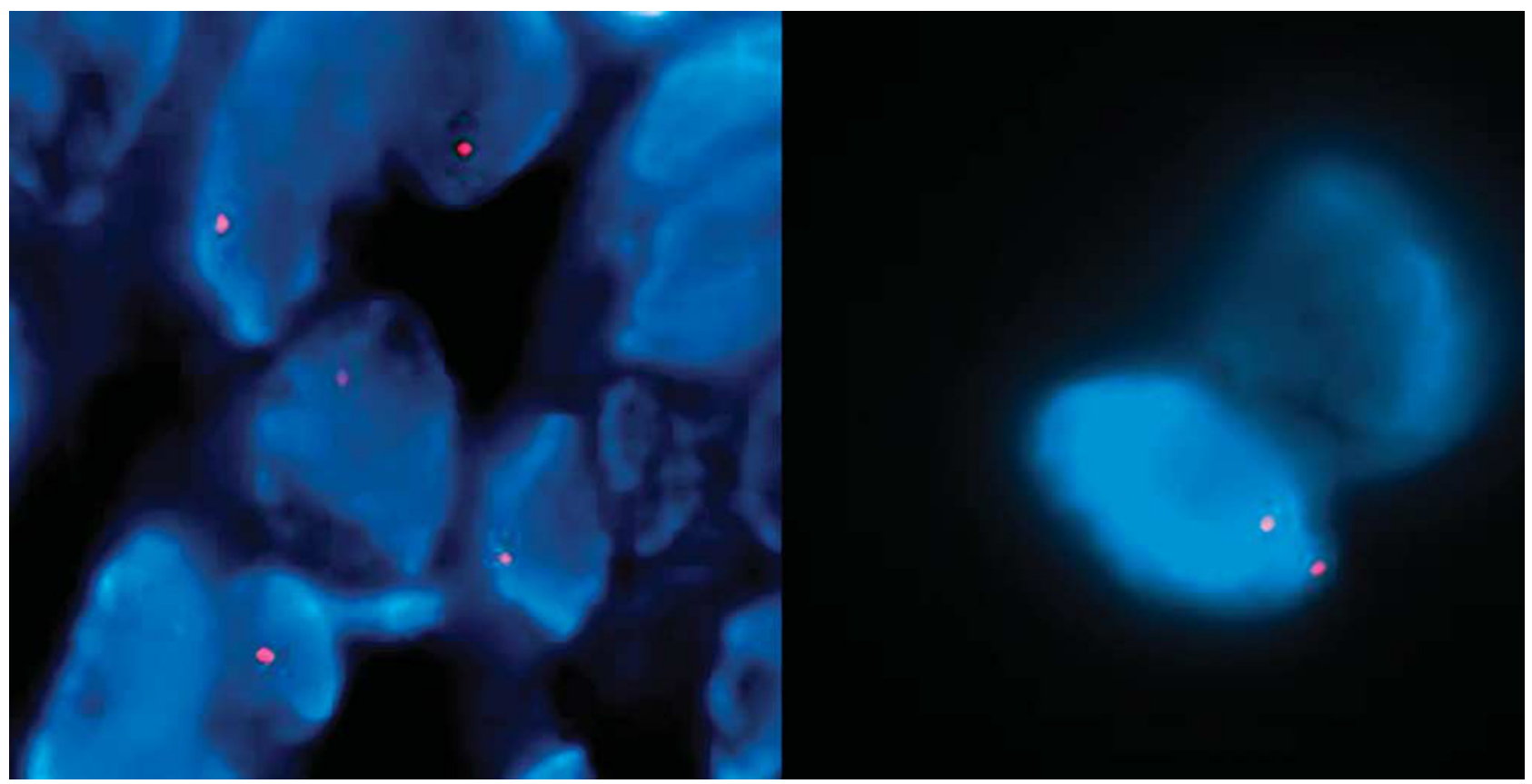

Figure 9 FISH analysis: monoallelic loss of $R B 1$ was found in all seven cases tested. A negative control with both alleles of $R B 1$ is seen on the right. 
spindle cells as characterized by Kandil et $a l^{6}$ and Chen and Fletcher ${ }^{8}$ and occurred also in the vulva. McCluggage et $a l^{18}$ depicted in their series one case of the vulva with marked nuclear pleomorphism resembling symplastic change in uterine leiomyoma.

The follow-up (6 months) was as in all other cases of our series unremarkable. This finding is in agreement with the reported cases. ${ }^{6,8}$ Therefore, the biological significance of atypia and sarcomatous transformation remains uncertain. ${ }^{8}$

One of the differential diagnoses of cellular angiofibroma is solitary fibrous tumor which can also include fat and shows almost always positivity for CD34. ${ }^{20}$ Hemangiopericytoma-like vessels were observed in a subset of cellular angiofibroma ${ }^{2,3,18}$ and we also could find this vascular pattern in three cases. We considered this alternative possibility in one of our cases occurring in the upper eyelid and showing strong positivity for CD34. The cells were arranged in a myxoid matrix, as also described for solitary fibrous tumor. ${ }^{21}$ However, our case consisted of evenly distributed spindle cell lipoma-like cells. A prominent vasculature, typically seen in cellular angiofibroma, with partly hyalinized vessels was existent, but hemangiopericytoma-like vessels were not present in this case.

Whereas losses on chromosome 13q have been detected in solitary fibrous tumor, cytogenetic analyses to date have not found any consistent genetic abnormalities. ${ }^{22-24}$

Superficial myofibroblastoma of the lower female genital tract probably belongs to the morphological spectrum of vulvovaginal stromal polyps. Variegated patterns are described including myxoid, lace-like, sieve-like, fascicular, or storiform. The collagenous stroma sometimes contains thick collagen bundles. ${ }^{25-27}$ Desmin is a discriminating marker as cellular angiofibromas are negative for this antibody. ${ }^{1-3,18,25-27}$

Angiomyofibroblastoma could also potentially be confused with cellular angiofibroma, because of its localization in the genital region. ${ }^{28-31}$ It is composed of more epithelioid and often plasmocytoid cells arranged in cords and nests preferentially around vessels. Mast cells can be abundant. The tumor cells express desmin and rarely CD34 and smooth muscle actin. ${ }^{28-32}$ Morphologically malignant cases resembling leiomyosarcoma or undifferentiated sarcoma have been reported. As described in cellular angiofibromas, none of these have metastasized to date, and one recurred 2 years later. ${ }^{33,34}$

Deep ('aggressive') angiomyxoma involves the pelvic region, tends to be quite large, and displays an infiltrative growth with entrapment of mucosal glands, fat, muscle, and nerves. The prominent vascular component shows hyalinization or hypertrophy. Myoid bundles, mostly adjacent to mediumsized vessels, are a typical finding. There is a variable positivity for desmin, smooth muscle actin, and CD $34 .^{28,31,35-38}$
Superficial angiomyxoma occurs among others in the genital region and possesses prominent myxoid stroma with delicate thin-walled vessels. Inflammatory cells, particularly neutrophils, are a diagnostic clue. Entrapment of an epithelial component is present in a third of the cases. This lesion may be positive for CD34. ${ }^{28,39,40}$

Juxtaarticular myxoma, most frequently located on the knee, arises particularly in men. This lesion shows a striking accumulation of mucinous material with poor cellularity. ${ }^{41}$ Our cases located on the knee showed mucoid degeneration, but they were more cellular with typical features of cellular angiofibroma. In one of them, we could show loss of $R B 1$ (Case 9).

Benign nerve sheath tumors, as schwannoma and neurofibroma, contain more wavy and buckled nuclei. Discriminating S100 positivity is never described in cellular angiofibroma. ${ }^{2,3}$ We confirmed this finding in our study group.

Expression of EMA, as seen in two out of six of our cases, could lead to the differential diagnosis of soft tissue perineurioma. The storiform, fascicular, and/or whorled growth pattern of spindle cells with delicate processes are characteristic for this lesion. ${ }^{42}$

In summary, we could extend the clinicopathological features of cellular angiofibroma including a morphologically sarcomatous transformed variant and further extragenital localizations. Moreover, the confirmation of the genetic relationship between cellular angiofibroma, mammary-type myofibroblastoma, and spindle cell lipoma suggests that these tumors are a spectrum of one entity. RB1 FISH analysis could be an ancillary tool for supporting these diagnoses, but the specificity is uncertain by now.

\section{Acknowledgements}

We thank the following pathologists who kindly provided case material and clinical follow-up when available: Dr S Bogner, Linz, Austria (Case 2); Dr D Schmidt, Mannheim (Case 7); Dr P Schwabbauer (Case 8), Dr J Zustin (Case 10), Dr S Ihlow (Case 9), Dr EW Herbst, Dr C König, Neubrandenburg (Case 13); Dr B Busch, Dinslaken (Case 6); Dr R Berndt, Ansbach (Case 5); Dr D Rothacker, Schwerin (Case 4); Dr C Kuhnen, Münster (Case 3); Dr G Jautzke (Case 1), Dr W Haedicke, Berlin (Case 24); Dr C Hallermann, Münster (Case 23); Dr K Petrow, Zwickau (Case 22); Dr A Niendorf, Hamburg (Case 21); Dr F Franke, Giessen (Case 20); Dr S Kribus, Hof (Case 19); Dr R Hinze, Schwerin (Case 18); Dr A Wellmann, Celle (Case 17); Dr R Inniger, Gummersbach (Case 16); Dr S Savin, Offenburg (Case 15); Dr T Heisig, Dr Progrebniak, Neunkirchen (Case 14); Dr K Junker, Dr F Brasch, Bremen (Case 12); Dr Weingardt-Kocher, Göppingen, Germany (Case 11); Dr E Ruijter, Arnhem The Netherlands (Case 25). 


\section{Disclosure/conflict of interest}

The authors declare no conflict of interest.

\section{References}

1 Nucci MR, Granter SR, Fletcher CDM. Cellular angiofibroma: a benign neoplasm distinct from angiomyofibroblastoma and spindle cell lipoma. Am J Surg Pathol 1997;21:636-644.

2 Laskin WB, Fetsch JF, Mostofi FK. Angiomyofibroblastoma like tumor of the male genital tract: analysis of 11 cases with comparison to female angiomyofibroblastoma and spindle cell lipoma. Am J Surg Pathol 1998;22:6-16.

3 Iwasa Y, Fletcher CDM. Cellular angiofibroma: clinicopathologic and immunhistochemical analysis of 51 cases. Am J Surg Pathol 2004;28:1426-1435.

4 Garijo MF, Val-Bernal JF. Extravulvar subcutaneous cellular angiofibroma. J Cutan Pathol 1998;25:327-332.

5 Val-Bernal JF, Rubio S, Garijo MF, et al. Extragenital subcutaneous cellular angiofibroma case report. APMIS 2007;115:254-258.

6 Kandil DH, Kida M, Laub DR, et al. Sarcomatous transformation in a cellular angiofibroma: a case report. J Clin Pathol 2009;62:945-947.

7 Eversole LR. Cellular angiofibroma of oral mucosa: report of two cases. Head Neck Pathol 2009;3:136-139.

8 Chen E, Fletcher CDM. Cellular angiofibroma with atypia and sarcomatous transformation: a clinicopathologic analysis of 13 cases. Am J Surg Pathol 2010;34:707-714.

9 Chan KW, Ghadially FN, Alagaratnam TT. Benign spindle cell tumour of the breast: a variant of spindle cell lipoma or fibroma of breast. Pathology 1984;16: 331-336.

10 Wargotz ES, Weiss SW, Norris HJ. Myofibroblastoma of the breast: sixteen cases of a distinctive benign mesenchymal tumor. Am J Surg Pathol 1987;11:493-502.

11 McMenamin ME, Fletcher CDM. Mammary-type myofibroblastoma of soft tissue. A tumor closely related to spindle cell lipoma. Am J Surg Pathol 2001;25: 1022-1029.

12 Dal Cin P, Sciot R, Polito P, et al. Lesions of $13 \mathrm{q}$ may occur independently of deletion of $16 q$ in spindle cell/pleomorphic lipomas. Histopathology 1997; 31:222-225.

13 Pauwels P, Sciot R, Croiset F, et al. Myofibroblastoma of the breast: genetic link with spindle cell lipoma. J Pathol 2000;191:282-285.

14 Maggiani F, Debiec-Rychter M, Vanbockrijck M, et al. Cellular angiofibroma: another mesenchymal tumor with 13q14 involvement, suggesting a link with spindle cell lipoma and (extra)-mammary myofibroblastoma. Histopathology 2007;51:410-412.

15 Maggiani F, Debiec-Rychter M, Verbeeck G, et al. Extramammary myofibroblastoma is genetically related to spindle cell lipoma. Virchows Arch 2006;449: 244-247.

16 Hameed M, Clarke K, Amer HZ, et al. Cellular angiofibroma is genetically similar to spindle cell lipoma: a case report. Cancer Genet Cytogenet 2007;177: 131-134.

17 Fletcher CDM, Martin-Bates E. Spindle cell lipoma: a clinicopathological study with some original observations. Histopathology 1987;11:803-817.
18 McCluggage WG, Ganesan R, Hirschowitz L, et al. Cellular angiofibroma and related fibromatous lesions of the vulva: report of a series of cases with a morphological spectrum wider than previously described. Histopathology 2004;45:360-368.

19 Dargent JL, de Saint Aubain N, Gomez Galdon M, et al. Cellular angiofibroma of the vulva: a clinicopathological study of two cases with documentation of some unusual features and review of the literature. J Cutan Pathol 2003;30:405-411.

20 Guillou L, Fletcher JA, Fletcher CDM, et al. Extrapleural solitary fibrous tumour and haemangiopericytoma, In: Fletcher CDM, Unni KK, Mertens F (eds). Pathology and Genetics of Tumors of Soft Tissue and Bone. World Health Organization classification of tumors: IARC Press: Lyon, 2002, pp 86-90.

21 De Saint Aubain Somerhausen N, Rubin BP, Fletcher CDM. Myxoid solitary fibrous tumor: a study of seven cases with emphasis on differential diagnosis. Mod Pathol 1999;12:463-471.

22 Miettinen MM, el-Rifai W, Sarlomo-Rikala M, et al. Tumor size-related DNA copy number changes occur in solitary fibrous tumors but not in hemangiopericytomas. Mod Pathol 1997;10:1194-1200.

23 Krismann M, Adams H, Jaworska M, et al. Benign solitary fibrous tumour of the thigh: morphological, chromosomal and differential diagnostics aspects. Langenbecks Arch Surg 2000;385:521-525.

24 Park MS, Araujo DM. New insights into the hemangiopericytoma/solitary fibrous tumor spectrum of tumors. Curr Opin Oncol 2009;21:327-331.

25 Laskin WB, Fetsch JF, Tavassoli FA. Superficial cervicovaginal myofibroblastoma: fourteen cases of a distinctive mesenchymal tumor arising from the specialized subepithelial stroma of the lower female genital tract. Hum Pathol 2001;32:715-725.

26 Ganesan R, McCluggage WG, Hirschowitz L, et al. Superficial myofibroblastoma of the lower female genital tract: report of a series including tumours with a vulval location. Histopathology 2005;46: 137-143.

27 McCluggage WG. Recent developments in vulvovaginal pathology. Histopathology 2009;54:156-173.

28 Nucci MR, Fletcher CDM. Vulvovaginal soft tissue tumors. Histopathology 2000;36:97-108.

29 Ockner DM, Sayadi H, Swanson PE, et al. Genital angiomyofibroblastoma. Comparison with aggressive angiomyxoma and other myxoid neoplasms of skin and soft tissue. Am J Clin Pathol 1997;107: 36-44.

30 Ito M, Yamaoka H, Sano K, et al. Angiomyofibroblastoma of the male inguinal region. Arch Pathol Lab Med 2000;124:1679-1681.

31 Fletcher CDM, Tsang WY, Fisher C, et al. Angiomyofibroblastoma of the vulva: a benign neoplasm distinct from aggressive angiomyxoma. Am J Surg Pathol 1992;16:373-382.

32 Laskin WB, Fetsch JF, Tavassoli FA. Angiomyofibroblastoma of the female genital tract: analysis of 17 cases including a lipomatous variant. Hum Pathol 1997;28:1046-1055.

33 Nielsen GP, Young RH, Dickersin GR, et al. Angiomyofibroblastoma of the vulva with sarcomatous transformation ('angiomyofibrosarcoma'). Am J Surg Pathol 1997;21:1104-1108.

34 Folpe AL, Tworek JA, Weiss SW. Sarcomatous transformation in angiomyofibroblastomas: a clinicopathological and 
immunohistochemical study of eleven cases. [Abstract]. Mod Pathol 2001;14:12A.

35 Tsang WJ, Chan JK, Fisher C, et al. Aggressive angiomyxoma. A report of four cases occurring in men. Am J Surg Pathol 1992;16:1059-1065.

36 Iezzoni JC, Fechner RE, Wong LS, et al. Aggressive angiomyxoma in males. A report of four cases. Am J Clin Pathol 1995;104:391-396.

37 Granter SR, Nucci MR, Fletcher CDM. Aggressive angiomyxoma: reappraisal of its relationship to angiomyofibroblastoma in a series of 16 cases. Histopathology 1997;30:3-10.

38 Fetsch JF, Laskin WB, Lefkowitz M, et al. Aggressive angiomyxoma. A clinicopathologic study of 29 female patients. Cancer 1996;78:79-90.
39 Fetsch JF, Laskin WB, Tavassoli FA. Superficial angiomyxoma (cutaneus myxoma). A clinicopathologic study of 17 cases arising in the genital region. Int J Gyn Pathol 1997;16:325-334.

40 Calonje E, Guerin D, McCormick D, et al. Superficial angiomyxoma: clinicopathologic analysis of a series of distinctive but poorly recognized cutaneous tumors with tendency for recurrence. Am J Surg Pathol 1999;23:910-917.

41 Meis JM, Enzinger FM. Juxta-articular myxoma: a clinical and pathological study of 65 cases. Hum Pathol 1992;23:639-646.

42 Hornick JL, Fletcher CDM. Soft tissue perineurioma. Clinicopathologic analysis of 81 cases including those with atypical features. Am J Surg Pathol 2005;29:845-858. 